Adverse events (AEs), including treatment-emergent AEs (TEAEs) and serious AEs (SAEs), were monitored throughout the study.

Results: Overall, $391 / 500$ pts screened met the inclusion criteria; $55 \%$ were female with a mean age of 48.8 years. At baseline, disease characteristics were generally consistent across treatment arms (Table).

At W24, DAS28-CRP response rates increased across all TIL treatment arms relative to PBO (Figure). After W24, response rates continued to increase and were sustained through W52, including in pts who switched from PBO to TIL.

From W0-W24/W25-W52, 50.4\%/39.9\% and $2.3 \% / 1.0 \%$ of pts experienced a TEAE and SAE, respectively. There were no reports of candidiasis, inflammatory bowel disease, major adverse cardiac events or elevated liver enzymes. From W0-W24, $1 \mathrm{pt}(0.3 \%)$ had urinary tract infection (TIL $100 \mathrm{mg}$ Q12W). From W25W52, 1 pt (0.3\%) had an intraductal proliferative breast lesion (TIL $20 \rightarrow 200 \mathrm{mg}$ $\mathrm{Q} 12 \mathrm{~W})$. One pt $(0.3 \%)$ discontinued before 24 weeks due to hypertension. No deaths were reported.

Table. Baseline disease characteristics related to DAS28-CRP

\begin{tabular}{|c|c|c|c|c|c|}
\hline & $\begin{array}{c}\text { TIL } 200 \mathrm{mg} \\
\text { Q4W } \\
\mathrm{n}=78\end{array}$ & $\begin{array}{c}\text { TIL 200 mg } \\
\text { Q12W } \\
n=79\end{array}$ & $\begin{array}{c}\text { TIL } 100 \mathrm{mg} \\
\text { Q12W } \\
\mathrm{n}=77\end{array}$ & $\begin{array}{c}\text { TIL } 20 \rightarrow \\
200 \mathrm{mg} \mathrm{Q12W} \\
n=78\end{array}$ & $\begin{array}{c}\mathrm{PBO} \rightarrow \mathrm{TIL} \\
200 \mathrm{mg} \mathrm{Q12W} \\
\mathrm{n}=79\end{array}$ \\
\hline hsCRP, mg/L & $7.8 \pm 18.6$ & $10.5 \pm 14.4$ & $10.6 \pm 20.0$ & $10.7 \pm 14.0$ & $13.0 \pm 20.8$ \\
\hline $\mathrm{ESR}, \mathrm{mm} / \mathrm{h}^{*}$ & $22.8 \pm 18.9$ & $22.5 \pm 19.8$ & $24.7 \pm 19.8$ & $27.2 \pm 20.7$ & $26.9 \pm 20.5$ \\
\hline Swollen joint count (66) & $10.4 \pm 7.4$ & $10.0 \pm 8.0$ & $11.0 \pm 8.2$ & $9.4 \pm 6.4$ & $11.8 \pm 9.8$ \\
\hline Tender joint count (68) & $16.6 \pm 11.9$ & $19.5 \pm 13.9$ & $21.3 \pm 14.8$ & $19.0 \pm 13.0$ & $19.7 \pm 14.7$ \\
\hline PtGA & $57.8 \pm 18.3$ & $61.1 \pm 20.7$ & $60.3 \pm 20.2$ & $61.9 \pm 17.4$ & $65.2 \pm 18.1$ \\
\hline
\end{tabular}

Data are reported as mean \pm standard deviation unless otherwise stated.

*Total pts analysed $(n)=71,69,70,68,62$, respectively.

ESR, erythrocyte sedimentation rate; hsCRP, high-sensitivity C-Reactive Protein; PBO, placebo; PtGA, Patient Global Assessment; pts, patients; Q4W, every 4 weeks; Q12W, every 12 weeks; TIL tildrakizumab.

Conclusion: Treatment with all doses of TIL increased the rate of DAS28-CRP responders in pts with active PSA and was well tolerated, suggesting a reduction in PsA-related disease activity for up to 52 weeks of treatment. Ongoing analyses will assess whether DAS28-CRP responses correlate with baseline clinical characteristics.

Figure. DAS28-CRP response rates across treatments and time points

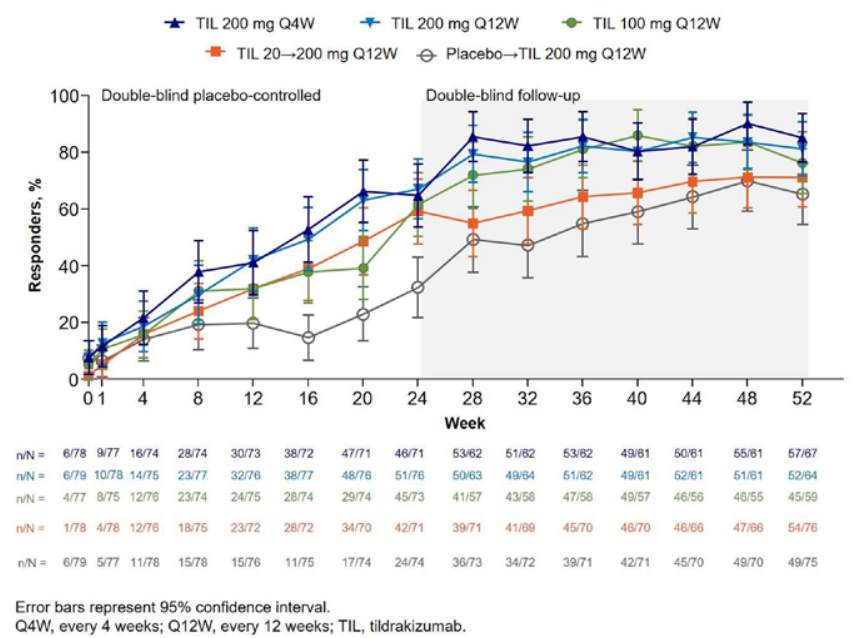

References:

[1] Reich K, et al. Lancet. 2017;390(10091):276-88.

[2] Taylor W, et al. Arthritis Rheum. 2006; 54(8):2665-73.

[3] Fransen J, et al. Ann Rheum Dis. 2004; 62:151.
Disclosure of Interests: Saima Chohan Employee of: Partner/physician at Arizona Arthritis and Rheumatology Associates, Arthur Kavanaugh Grant/research support from: AbbVie, Amgen, Eli Lilly, Novartis, Janssen, Pfizer, Gilead, UCB Consultant of: AbbVie, Amgen, Eli Lilly, Novartis, Janssen, Pfizer, Gilead, UCB, Vibeke Strand Consultant of: AbbVie, Amgen, Biogen, Celltrion, Consortium of Rheumatology Researchers of North America, Crescendo Bioscience, Eli Lilly, Genentech/Roche, GlaxoSmithKline, Hospira, Janssen, Merck, Novartis, Pfizer Regeneron Pharmaceuticals, Inc., Sanofi, UCB, Richard C Chou Consultant of: Sun Pharmaceutical Industries, Inc, Alan M Mendelsohn Shareholder of: Johnson and Johnson, Employee of: Sun Pharmaceutical Industries, Inc, Stephen Rozzo Employee of: Sun Pharmaceutical Industries, Inc, Philip J Mease Grant/research support from: Abbott, Amgen, Biogen Idec, BMS, Celgene Corporation, Eli Lilly, Novartis, Pfizer, Sun Pharmaceutical, UCB - grant/research support, Consultan of: Abbott, Amgen, Biogen Idec, BMS, Celgene Corporation, Eli Lilly, Novartis, Pfizer, Sun Pharmaceutical, UCB - consultant, Speakers bureau: Abbott, Amgen Biogen Idec, BMS, Eli Lilly, Genentech, Janssen, Pfizer, UCB - speakers bureau DOI: 10.1136/annrheumdis-2020-eular.3907

\section{AB0804 PREGNANCY AND PSORIATIC ARTHRITIS: A SYSTEMATIC LITERATURE REVIEW OF DISEASE ACTIVITY AND ADVERSE PREGNANCY OUTCOMES}

Y. Meißner ${ }^{1}$, T. Rudi ${ }^{1}$, R. Fischer-Betz ${ }^{2}$, A. Strangfeld ${ }^{1}{ }^{1}$ Deutsches RheumaForschungszentrum (DRFZ), Berlin, Germany; ${ }^{2}$ Department and Hiller Research Unit of Rheumatology, Heinrich-Heine University, Düsseldorf, Germany

Background: There is little robust evidence on the course of pregnancy and its outcomes in women with psoriatic arthritis (PsA) on which recommendations for the management of these patients could be based.

Objectives: To review available data on disease activity during pregnancy and adverse pregnancy outcomes in women with PsA.

Methods: Systematic literature search within the databases Pubmed and Embase using the keywords 'psoriatic arthritis' and 'pregnan*/ obstetr*/ matern*/ gestation*/ deliver*/ abortion*/ reproduct*/ birth/ parity'. All full text articles published until 31 Dec 2019 were systematically evaluated by 2 reviewers. All studies including at least 5 pregnant PsA patients and reporting on disease activity and/ or obstetric outcomes were considered.

Results: The review of 592 search results revealed 13 eligible publications reporting on a total of 2332 pregnancies in PsA. Nine studies reported disease activity during and after pregnancy using differing instruments (table 1). Three of them reported an increase in the proportion of women with moderate to severe activity postpartum compared to pregnancy. Another 3 studies described a worsening of the arthritis in $15-32 \%$ and in the psoriatic activity in $4-9 \%$ of patients during pregnancy and postpartum in $33-50 \%$ and $27-43 \%$ of patients, respectively.

Table 1. Study characteristics

\begin{tabular}{|c|c|c|c|}
\hline Study & Data source & $\begin{array}{c}\text { No. of } \\
\text { pregnancies }\end{array}$ & $\begin{array}{l}\text { Disease activity } \\
\text { instruments }\end{array}$ \\
\hline Berman, 2018 & Hospital records & 35 & Synovitis \\
\hline Bröms, 2018 & National registries & 964 & - \\
\hline Eudy, 2019 & $\begin{array}{c}\text { Hospital records + } \\
\text { questionnaires }\end{array}$ & 37 & $\begin{array}{c}\text { Patient reported arthritis + } \\
\text { psoriatic activity }\end{array}$ \\
\hline Mork, 2019 & National registries & 130 & - \\
\hline Mouyis, 2017 & Hospital records & 16 & Physician global activity \\
\hline Murray, 2019 & Hospital cohort* & 18 & DAS28-CRP3 \\
\hline Ostensen, 1988 & Hospital cohort* & 12 & Composite score \\
\hline Polachek, 2017 & Hospital cohort* & 42 & SJC/ TJC, PASI \\
\hline Polachek, 2019 & $\begin{array}{r}\text { Hospital cohort }+ \\
\text { questionnaires }\end{array}$ & 151 & Patient reported PsA activity \\
\hline Remaeus, 2019 & National registries & 541 & - \\
\hline Smith, 2019 & Cohort* ${ }^{\star}$ & 117 & HAQ, RAPID3 \\
\hline Strouse, 2019 & Claims data & 161 & - \\
\hline Ursin, 2019 & Cohort* & 108 & DAS28, BASDAI \\
\hline
\end{tabular}

*Prospective study

Table 2. Obstetric outcomes

\begin{tabular}{|c|c|c|c|c|c|c|c|c|}
\hline Study & $\begin{array}{c}\text { Comparator: Pregnant women } \\
\text { without ... }\end{array}$ & $\begin{array}{l}\text { Repor- } \\
\text { ted as }\end{array}$ & (Pre-) Eclampsia & $\begin{array}{l}\text { Gesta- } \\
\text { tional diabetes }\end{array}$ & $\begin{array}{l}\text { Elective Caesarean } \\
\text { section }\end{array}$ & Preterm birth & SGA & LBW \\
\hline Bröms & ...p psoriasis & $\mathrm{HR}$ & $1.49(1.08-2.05)$ & $1.21(0.79-1.87)$ & $1.47(1.18-1.81)$ & $1.25(0.94-1.65)$ & $0.72(0.42-1.22)$ & $1.07(0.75-1.52)$ \\
\hline Mork & ... Spondyloarthritis & OR & $1.03(0.23-4.57)$ & - & $1.01(0.47-2.19)$ & $1.24(0.54-2.83)$ & $1.72(0.98-3.02)$ & - \\
\hline Remaeus & ... PsA & $\mathrm{HR}$ & $1.21(0.78-1.88)$ & $1.26(0.54-2.94)$ & $1.47(1.10-1.97)$ & $1.63(1.17-2.28)$ & $1.06(0.61-1.84)$ & - \\
\hline Smith & $\begin{array}{c}\text {... auto-immune/ other chronic } \\
\text { diseases }\end{array}$ & RR & $2.22(0.98-5.04)$ & $1.41(0.70-2.87)$ & - & $1.69(0.94-3.03)$ & - & $1.52(0.76-3.04)$ \\
\hline Strouse & ... rheumatic diseases & $\mathrm{HR}$ & - & - & - & $1.77(1.15-2.73)$ & $1.24(0.75-2.06)$ & - \\
\hline
\end{tabular}

Abbreviation: HR, Hazard ratio; OR, Odds ratio; $R R$, risk ratio. 
Adjusted analyses did not show an increased risk for gestational diabetes, small for gestational age (SGA) and low birth weight (LBW) in PsA patients (table 2). However, estimates for other obstetric outcomes diverged.

Conclusion: Individual studies showed a trend towards increased disease activity after pregnancy in PsA patients but due to the heterogeneity of the instruments used, it is difficult to summarise the single results. No signal for specific adverse pregnancy outcomes was identified. However, a higher risk for (pre)eclampsia, elective caesarean section and preterm birth cannot be ruled out. Differences in studies (e.g. primary vs secondary data) limit statements on obstetric outcomes. Harmonization of approaches and instruments is crucial in order to enable future joint data analyses and meta-analyses. In particular, a standardised instrument for assessing disease activity of PsA that takes into account the particularities of pregnancy is needed.

Funding: This work was supported by a research grant from FOREUM Foundation for Research in Rheumatology.

Disclosure of Interests: Yvette Meißner Speakers bureau: Pfizer, Tatjana Rudi: None declared, Rebecca Fischer-Betz Consultant of: UCB, Speakers bureau: Abbvie, Amgen, Biogen, BMS, Celgene, Chugai, GSK, Janssen, Lilly, Medac, MSD, Novartis, Roche, UCB, Pfizer., Anja Strangfeld Speakers bureau: AbbVie, BMS, Pfizer, Roche, Sanofi-Aventis

DOI: 10.1136/annrheumdis-2020-eular.3076

\section{AB0805 $\quad$ PREMATURE ATHEROSCLEROSIS IN PSORIATIC ARTHRITIS (PSA) PATIENTS AND ITS POSSIBLE ASSOCIATION WITH INSULIN RESISTANCE \& SERUM LEPTIN LEVEL}

N. Mohannad $^{1}$, M. Zehairy ${ }^{2}$, M. Darwish ${ }^{3} .{ }^{1}$ Faculty of Medicine, Alexandria University Hospitals, Internal Medicine Department, Rheumatology Unit, Alexandria, Egypt; ${ }^{2}$ Faculty of Medicine, Alexandria University, internal Medicine Department, Rheumatology Unit, Alexandria, Egypt; ${ }^{3}$ Alexandria Armed Force Hospital, Alexandria, Egypt

Background: PsA is a heterogeneous inflammatory arthritis. Patients (pts) with PsA suffer from associated cardiovascular disease, obesity, metabolic syndrome, diabetes (DM), osteoporosis. In psoriasis, leptin has been shown to stimulate keratinocyte proliferation, expression of adhesion molecules and angiogenesis.

Objectives: To detect the presence of premature atherosclerosis in PsA pts, measure HOMA-IR as a reflection of insulin resistance (IR) and serum leptin (LEP) level \& to detect their association with the presence of premature atherosclerosis in PsA pts.

Methods: 45 PsA pts (classified according to CASPAR Criteria) \& 45 healthy subjects as controls were included. Pts were subjected to history taking, clinical examination to determine body mass index (BMI), the clinical type of PsA, distribution, involved body surface area (BSA), measuring the Psoriasis Area and Severity Index (PASI) and Disease Activity in PSoriatic Arthritis: DAPSA score. Routine laboratory, fasting insulin (FI), fasting blood glucose (FBG) to calculate HOMA-IR,total cholesterol (TC), HDL, LDL, Triglycerides (TG), serum LEP, carotid Doppler to determine Carotid intima-media thickness (CIMT) \& presence or absence of plaques were done. Exclusion: DM, RA, SLE, smoking, postmenopausal females, HCV infection, morbid obesity

\begin{tabular}{lcc}
\hline CIMT & Person correlation coefficient & p-value \\
\hline BMI & 0.095 & 0.371 \\
Duration of disease (years) & 0.179 & 0.239 \\
BSA score & 0.12 & 0.434 \\
PASI & 0.186 & 0.221 \\
FBG & 0.059 & 0.582 \\
WBC & -0.104 & 0.329 \\
Platelet & 0.022 & 0.835 \\
Hb & -0.106 & 0.319 \\
HDL & 0.505 & $0.000^{\star *}$ \\
LDL & 0.382 & $0.000^{\star *}$ \\
TC & 0.275 & $0.009^{* *}$ \\
Triglyceride & 0.06 & 0.577 \\
SGOT & 0.03 & 0.776 \\
SGPT & 0.033 & 0.754 \\
Serum leptin & 0.537 & $0.0001^{\star *}$ \\
HOMA IR & 0.446 & $0.000^{* *}$ \\
ESR & 0.351 & $0.001^{* *}$ \\
CRP & 0.320 & $0.002^{* *}$ \\
Urea & 0.445 & 0.784 \\
Creatinine & 0.392 & 0.954 \\
Uric acid & 0.034 & 0.748 \\
FI & 0.431 & $0.000^{* *}$ \\
\hline
\end{tabular}

Results: Mean BMI $22.51 \pm 1.69$ and $23.46 \pm 1.82 \mathrm{~kg} / \mathrm{m}^{2}$, no statistical significance $(P=0.205)$

Mean BSA $5.9 \pm 3.1 \%$, DAPSA score $(13.98 \pm 4.7)$, PASI score: $88.9 \%$ (40 pts) had mild to moderate PASI, 5 had severe disease $(8.6 \pm 4.8)$

TC, LDL and TG were higher in pts, while HDL was higher in controls $(P=0.0003$ $0.0001,0.00001 \& 0.05)$.

A significance between 2 groups regarding LEP $(P=0.00001)$, ranging from 2-16.99 $(9.7 \pm 4.5)$ in group I and 1.35-1.78 $(1.6 \pm 0.1) \mu \mathrm{g} / \mathrm{ml}$ in controls. Normal: 2.6-8.35

$\mathrm{FI} \& \mathrm{HOMA} I \mathrm{R}$ were significantly higher in $\mathrm{PsA}$ group $(\mathrm{P}=0.001,0.00001)$

The mean CIMT $1.1 \pm 0.3 \mathrm{~mm}$ and in group II $0.8 \pm 0.1 \mathrm{~mm} .14 \mathrm{pts}(31.1 \%)$ had plaque, while $68.9 \%$ \& all controls had no plaques, with a significance regarding CIMT \& presence of plaques $(P=0.011 \& 0.0041)$.

A positive statistical significance between LEP and dd ( $P=0.001), B S A, P A S I$ and DAPSA ( $P=0.007,0.003,0.001)$ but not with age, BMI $(P=0.98 \& 0.88)$.

There was no statistical significance between LEP and FBG, HbA1C, HOMA IR, FI, CBC ( $P>0.05)$, or between LEP and TC, TG, HDL, LDL $(P=0.438,0.390$, $0.699,0.050)$, liver enzymes, renal functions, ESR and CRP.

There was statistical positive correlation between LEP and CIMT ( $P=0.0001)$, but not with the presence of plaques $(\mathrm{P}=0.846)$

CIMT and other variables: Table 1

DAPSA: there was no statistical significance with TC, HDL, LDL and TG $(P=0.51,0.876,0.717 \& 0.255)$, but a statistically significance with LEP and $\operatorname{CIMT}(p=0.001 \& 0.009)$. Pts with higher score had higher LEP and increased CIMT.

PASI: there was no significance between TC, HDL, LDL, TG $(P=0.724,0.157$, $0.651 \& 0.374)$ or CIMT $(p=0.290)$ in mild-moderate and severe PASI. LEP was significantly higher in severe PASI score $(P=0.001)$

Conclusion: The presence of abnormal lipid profile, IR, increased CIMT, high disease activity and increased LEP may be considered as useful criteria for early recognition and thus prevention of atherosclerosis in PsA pts.

References:

[1] Miller I M, et al. Meta-analysis of psoriasis, cardiovascular disease and associated risk factors. J Am Acad Dermatol 2013

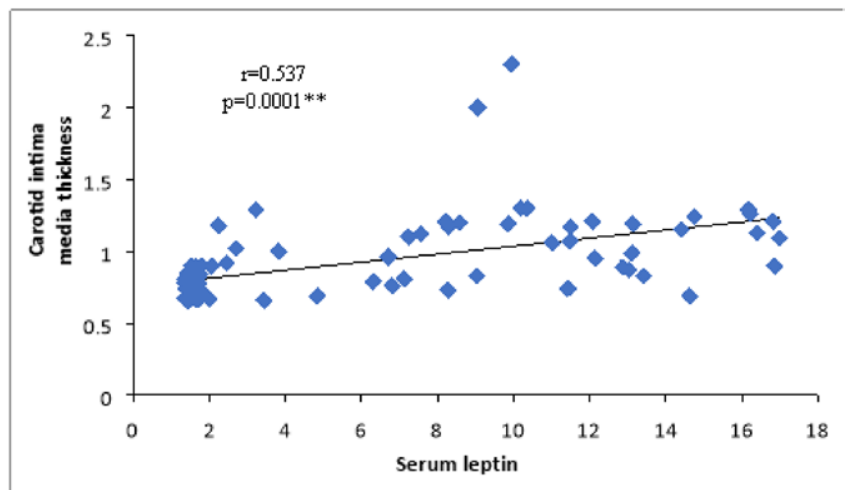

Disclosure of Interests: None declared DOI: 10.1136/annrheumdis-2020-eular.5883

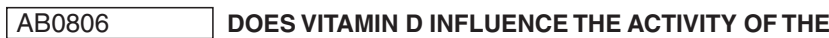 DISEASE IN PATIENTS WITH PSORIATIC ARTHRITIS?}

L. Montolio-Chiva ${ }^{1}$, A. V. Orenes Vera ${ }^{1}$, M. Aguilar-Zamora ${ }^{2}$, C. VergaraDangond $^{3}$, I. Vázquez-Gómez ${ }^{1}$, E. Flores ${ }^{1}$, A. Sendra-García ${ }^{1,4}$,

À. Martínez-Ferrer ${ }^{1}$, E. Valls-Pascual ${ }^{1}$, D. Ybáñez-García ${ }^{1}$, V. Núñez-Monje ${ }^{1}$, I. Torner-Hernández ${ }^{1}$, J. J. Alegre-Sancho ${ }^{1} .{ }^{1}$ Universitary Peset Doctor Hospital, Valencia, Spain; ${ }^{2}$ Sagunto Hospital, Valencia, Spain; ${ }^{3}$ Universitary Infanta Sofía Hospital, Madrid, Spain; ${ }^{4}$ Foundation for the Promotion of Sanitary and Biomedical Research in the Valencian Community (FISABIO), Valencia, Spain

Background: Several studies have shown an inverse relationship between vitamin D levels (25OHD) and disease activity in patients with rheumatoid arthritis (RA). However, the existing data in patients with psoriatic arthritis (PsA) are poor, and they use the DAS28 index as a peripheral joint activity marker by extrapolation with RA.

Objectives: To analyze the relationship between $250 \mathrm{HD}$ levels, disease activity and functional capacity in patients with PsA.

Methods: Transversal, observational, descriptive study. We included PsA patients with peripheral joint involvement. We collected demographic variables (gender, age), clinical variables [follow-up, received treatments, TJC 